Forthcoming in Journal of the American Philosophical Association

Accepted Version

\title{
What Sort of Imagining Might Remembering Be?
}

\author{
Peter Langland-Hassan
}

Abstract: This paper unites current philosophical thinking on imagination with a burgeoning debate in the philosophy of memory over whether episodic remembering is simply a kind of imagining. So far, this debate has been hampered by a lack of clarity in the notion of 'imagining' at issue. Several options are considered and constructive imagining is identified as the relevant kind. Next, a functionalist account of episodic memory is defended as a means to establishing two key points: first, one need not defend a factive (or "causalist") view of remembering in order to hold that causal connections to past experiences are essential to how rememberings are typed; and, second, current theories that equate remembering with imagining are in fact consistent with a functionalist theory that includes causal connections in its account of what it is to remember. This suggests that remembering is not a kind of imagining and clarifies what it would take to establish the contrary.

I.

Suppose that two parties disagree over whether events A and events B are events of the same kind $\mathrm{C}$. To join their debate, we'll need to know three things:

1) What are the events in group $\mathrm{A}$ ?

2) What are the events in group $B$ ?

3) What is it to be an event of kind $\mathrm{C}$ ?

In this debate, it is agreed that (1) and (2) get different answers. Pointing to events A and then to events $\mathrm{B}$, our disputants agree that they are distinct sets of events. No one is proposing that the group A events just are the group B events viewed from another angle. Where they disagree is in whether the events in each group are all events of kind C. Those we will call the continuists 
hold that A-events and B-events are continuous in the sense that they are all events of kind $\mathrm{C}$. Their foes, the discontinuists, hold that A-events and B-events are not all events of kind C. The (dis)continuism debate is the debate between these parties.

Now, clearly, if our two parties have different ideas about what it is to be an event of kind $\mathrm{C}$, subsequent debates over whether both $\mathrm{A}$-events and B-events are $\mathrm{C}$-events will be unproductive. Our disputants, to be disputants, need to agree on a characterization of what it is to be an event of kind C. Only then can they debate whether A-events and B-events are all of that kind. Note well: the agreed characterization of $\mathrm{C}$-events cannot entail an obvious verdict in either direction. If it does, one side will cry foul. They will say, "The question was never whether A events and B events are C events in that sense of ' $\mathrm{C}$ '.'

So much for the form of argument. We can now fill in some variables. At issue is the relationship of episodic remembering to imagining: specifically, are events of episodic remembering (A) and certain events of imagining (B) both events of kind C? Both partiescontinuists and discontinuists - agree that events in group A are cases of episodic memory: events whereby a person remembers an episode from their personal past. While disagreeing on the ultimate nature of episodic memory, both sides agree on paradigmatic cases: Joe forms auditory and visual imagery in representing a heated conversation he had earlier today; Jane recalls her college graduation, visualizing the way things looked as she walked across the stage toward an administrator holding her diploma. By means of such descriptions, they pick out the events in group A. We can expect disputes over particular cases. Some may see episodic memory as factive, in the sense that a person cannot episodically remember something that did not happen (Bernecker, 2010; Debus, 2008); they will not include cases of misremembering in group A. Others allow that as least some misremberings (or "unsuccessful" cases of memory) still fall within group A (Fernández, 2019; Michaelian, 2016c). But all sides agree that cases of successfully episodically remembering an event fall into class A; and they agree fairly well about when and how often these occur. Note that, in our terms, episodic memory ("EM") will be shorthand for a certain type of occurrent mental episode - namely, episodic rememberings. This contrasts with using 'episodic memory' as a label for a static memory store or general cognitive faculty. 
Now to the events in group B. In recent years, when philosophers and psychologists have asked whether episodic rememberings and (episodic) imaginings are events of the same kind, they have had a certain set of events in mind as the relevant "imaginings." Without offering a metaphysics of the kind, we can point to paradigmatic cases: Joe regrets the argument he got into earlier today and imagines what would have happened had he withheld his sarcastic remark; Jane's pulse quickens as she imagines what it would have been like had she tripped and fallen in her journey across the graduation stage. These are typical cases of what has been called episodic counterfactual thought; they are imaginings of ways things could have gone differently in one's personal past (De Brigard, Addis, Ford, Schacter, \& Giovanello, 2013). Also among the events of group B are cases of episodic future thought: Joe imagines how his apology will be received later this evening; Jane, a newly appointed dean, imagines what it will be like to hand out diplomas during the spring graduation ceremony. These episodic future thoughts ("EFT") combine with episodic counterfactual thoughts ("ECT") to fill out the events in group B. Both continuists and discontinuists agree that the B-group events, so picked out, are distinct from the A-group events.

Our characterization of the (dis)continuism debate is starting to take shape. The question is: are episodic rememberings (EM), on the one hand, and episodic counterfactual thoughts (ECT) and episodic future thoughts (EFT), on the other, all events of the same kind? Are they all events of kind $\mathrm{C}$ ?

That leaves us at our third question's doorstep: what is it to be an event of kind C?

As a warmup to answering, suppose that mental event is kind C. In that case, it is obvious that A-events and B-events are all events of kind C. Not only that, we could say that Aevents are B-events are fundamentally the same kind of event. For falling together within the class of mental events - and being so distinguished, together, from sporting, political, and other kinds of events - makes two events fundamentally the same kind of thing. And yet, this fundamental similarity is irrelevant to the (dis)continuism debate. Neither side questioned whether the A events and B events are all mental events. This shows the importance of explicitly specifying kind C. We cannot simply ask whether the A-events and B-events are fundamentally the same kind of event. 
It might be responded that we can limit the class of kinds we are interested in to psychological (or, alternatively, mental) kinds, and then ask whether A-events and B-events are events of the same fundamental psychological kind. This would circumvent the problem just encountered. Yet this requires there to be just one fundamental level of psychological analysis such that, if two events are of the same type at that level of analysis (or within that taxonomic system), then they are fundamentally the same type of state - even if, on other taxonomic systems, they are seen as distinct kinds of states. However, there are multiple contenders for being a fundamental psychological taxonomic system. There are folk psychological kinds (such as "belief" "desire" "judgment" and "imagining"); there are cognitive kinds (such as "working memory" and "forward models"); there are region-of-neural-activation kinds (such as "activation in left inferior frontal gyrus" or "activation in hippocampus"); there are neurocognitive kinds (such as "the default mode network," and (perhaps) "episodic construction system"), and more. Nor is there obvious reason to think there cannot be multiple fundamental taxonomic systems relevant to typing psychological states. (See Robins (2020) for further discussion of this point as it pertains to the (dis)continuism debate).

So then, there is no dodging question (3) by refusing to specify the kind in advance. Our question remains: what sort of kind is kind $\mathrm{C}$, such that it is both debatable and important to determine whether events in group A ("A-events") and events in groups B ("B-events") are all events of kind C?

The recent proposal generating controversy is that kind $\mathrm{C}$ is imagining. Continuists propose that EM are simply "imaginings of one's personal past," that fall together with ECT and EFT in a general class of "imaginings" or "perceptual simulations" (Addis, 2020; Michaelian, 2016c). "We tend to assume that it is one thing to genuinely remember the past and another to imagine it," observes Kourken Michaelian, a prominent defender of continuism. "But that turns out not to be the case" (2016c, p. 120). Different forms of empirical evidence are put forward in support of this claim, including that patients with deficits in autobiographical memory show comparable deficits in imagining future scenarios (Hassabis, Kumaran, Vann, \& Maguire, 2007; Hassabis \& Maguire, 2009), that a core network of neural regions activated during autobiographical memory are similarly activated when planning future actions (Schacter \& Addis, 2007; Schacter, Addis, \& Buckner, 2007; Szpunar, Watson, \& McDermott, 2007), and 
that autobiographical memory and the ability to mentally project oneself into the future develop in children at roughly the same age (Atance, 2008). Evidence that errors are common in episodic memory and that one's sense of whether one is remembering can be manipulated in predictable ways (Garry, Manning, Loftus, \& Sherman, 1996; Loftus \& Pickrell, 1995), has been thought to further erode the distinction between EM and EFT/ECT and to thereby favor the conclusion that "remembering the past and imagining the future are strictly continuous" (Michaelian, 2016a, p. $62)$.

Nevertheless, we cannot assess whether such evidence is good evidence for the hypothesis that EM and EFT/ECT are all imaginings until we can clearly explain what we mean to conclude in calling these events imaginings. To do the latter, we will need to specify what it is to be an imagining in the relevant sense.

II.

It is a truth universally acknowledged: there are different kinds of imaginings, corresponding to different senses of the term 'imagines' (Arcangeli, 2018; Kind, 2016; Van Leeuwen, 2013). If we want to know what it is to be of kind C, we will have to specify which sense of 'imagining' we have in mind. This essential task is often neglected in the (dis)continuism debate. (Robins (2020) is a recent exception.) The omission occurs on both sides of the debate. Michaelian (2016c) stresses that his continuist simulation theory "simply equates remembering with imagining the past," without specifying what exactly he means by 'imagining' (2016, p. 110). And Denis Perrin, in a paper supporting discontinuism, explains that "strong discontinuism rejects the existence of something such as one genus of the episodic thought," and holds instead that EM and EFT are "different in nature, one being memory and the other imagination"- again without specifying the sense in which only EFT qualifies as imagination (2016, p. 41).

The three sub-sections to come consider three distinct senses of the term 'imagining' common in the philosophical literature on imagination: imagistic imagining, attitudinal imagining, and constructive imagining (Currie \& Ravenscroft, 2002; Kind, 2016; LanglandHassan, 2020; Van Leeuwen, 2013, 2014). Our question will be which, if any, of these senses of 'imagining' captures what is at issue in the (dis)continuism debate. 


\section{Imagistic Imagining}

We can begin with imagistic imagining. Everything said here about imagistic imagining can equally be said of "sensory" or "perceptual" imagining, as those terms tend to be used (as in, e.g., Peacocke (1985), Noordhof (2002), Martin (2002) and Byrne (2007)). These remarks will also apply to "perception-like imagining" as Currie \& Ravenscroft (2002, p. 24-27) use that term. (For Currie \& Ravenscroft (2002), perception-like imagining is just one species of a broader class of "recreative" imaginings. Others in that class are "belief-like imaginings," which will be captured by the discussion of attitudinal imagining, below.) Imagistic imagining requires, as a necessary feature, the use of mental imagery-imagery keyed to some sense modality or other. This much is uncontroversial among theorists working on imagination. Less settled are the questions of how to define mental imagery, and whether using mental imagery is sufficient for imagistic imagining or, instead, merely necessary. Mental imagery is generally thought of as a kind of endogenously caused perception-like mental state. Bence Nanay usefully characterizes it as "perceptual processing that is not triggered by corresponding sensory stimulation in a given sense modality" (2018, p. 127). While questions can be raised for such definitions, we needn't query them here.

As noted, some hold that any active use of mental imagery is an instance of imagistic imagining (Currie \& Ravenscroft, 2002, pp. 24-27; Langland-Hassan, 2015, 2020; Van Leeuwen, 2013), whereas others insist that only some uses of mental imagery qualify (Arcangeli, 2019; Kind, 2001). Typically, the reason given for thinking that only some uses of imagery are imagistic imaginings is that only some involve a person's taking the relevant (imaginative) attitude toward a content represented with mental imagery. To the extent that those concerns are relevant to the (dis)continuism debate, we can confront them when discussing imagining in the attitudinal sense (below). For now we can focus on the still common view that any use of mental imagery is a case of imagistic (or sensory, or perceptual) imagining.

What becomes of the (dis)continuism debate if we take kind $\mathrm{C}$ to be imagistic imagining? It looks as though we have no debate at all. Discontinuists accept that EM and EFT/ECT, often, or even always, make use of mental imagery. (See, e.g. Debus (2014, pp. 333-334)). Nor do continuists make their case by arguing that EM, like EFT/ECT, involves mental imagery. All 
sides assume as much. So, if there is a substantive debate afoot concerning whether EM and EFT/ECT are continuous in being fundamentally the same kind of mental state, the relevant kind is not imagistic imagining.

\section{Attitudinal imagining}

To imagine, in the attitudinal sense, is to take a certain attitude - the attitude of imagining — toward a content (Kind, 2016; Langland-Hassan, 2020; Liao \& Doggett, 2014; Van Leeuwen, 2013). What are we saying about someone when we say that they are imagining a content? A popular proposal is that the attitude of imagining is more like the attitude of belief than like desire, insofar as it is a cognitive (and not conative) state. Cognitive states are often distinguished from desire and other conative states by their "mind-to-world" direction of fit (Searle, 1983). To have a mind-to-world direction of fit is to represent the world as being a particular way, and, thus, to be in epistemic need of revision if the world is not that way. Conative states, like wishes and desires, are held to contrast in having a world-to-mind direction of fit, in the sense that the role of the state is to motivate its possessor to bring the world into a condition that matches the content of the state. So, for instance, a belief that there is cake mix in the pantry is false, and in need of revision, when there is no cake mix in the pantry; whereas, a desire that cake mix is in the pantry plays the role of motivating the person who has it to bring there to be cake mix in the pantry and is not false or in need of revision when there is no cake mix in the pantry.

Now suppose that someone imagines that cake mix is in the pantry. Most philosophers hold that such an imagining, like a belief with the same content, represents cake mix as being in the pantry - that it has a mind-to-word direction of fit. However, they also deny that such an imagining is false, inaccurate, or in epistemic need of revision, in cases where there is no cake mix in the pantry. This creates an instability in the definition of attitudinal imagining, as it is not clear what it is to represent the world as being some way (like a belief) while, at the same time, not being epistemically defective when the world is not that way (like a desire). If it is not the role of imaginings to represent the world as it really is (or was, or will be), what are we saying about attitudinal imaginings when we say that, like beliefs, they (really) represent the world as being some way? 
The notion of fictionality is often introduced as part of the answer. Neil Van Leeuwen proposes that attitudinal imaginings occur when someone "takes a cognitive attitude toward [the proposition] $c$ that nevertheless treats $c$ as somehow fictional” (2013, p. 221). And Amy Kind (2016) characterizes attitudinal imaginings as having a "mind-to-world direction of fit," where the relevant world is "best understood to be a make-believe or fictional world rather than the actual world" (p. 5). Questions persist. What is it to represent a proposition as "somehow fictional"? Which fictional world is an arbitrary daydream or fantastical imagining supposed to fit? Can imaginings fail to match their designated fictional world? How would we know if that occurred?

This is not the place to fully explore these questions. It suffices to see that the best we can do in characterizing attitudinal imaginings, without getting submerged in deep theorizing, is to describe them as mental events where we represent a certain content without thereby taking the world to be as we represent. This meshes with the most general definition of imagining provided by Liao \& Gendler (2020) in the Stanford Encyclopedia of Philosophy: "To imagine is to represent without aiming at things as they actually, presently, and subjectively are." Such characterizations are neutral on the question of whether we must make use of mental imagery in the process of representing such contents; and, indeed, philosophers are divided on that question (Kind, 2001; Langland-Hassan, 2015, 2020; Van Leeuwen, 2013; Williamson, 2016). We can therefore leave open whether all attitudinal imaginings, only some, or none at all are also imagistic imaginings, as defined above. Assuming - as many explicitly allow (LanglandHassan, 2015, 2020; Van Leeuwen, 2013; Kind, 2001) — that at least some imagery-involving mental states are attitudinal imaginings, we can now return to our main question to ask whether the (dis)continuism debate concerns whether EM, EFT, and ECT are continuous in the sense of all being attitudinal imaginings.

Here the answer is a clear no. Episodic memories are events where we represent the world as having been a certain way. Like beliefs about the past, they are considered defective, or in need of revision (or, on factive views of remembering, not memories at all), when the world was not the way they represent it as having been. This much is granted by continuists and discontinuists alike. For instance, Michaelian (2016c) explains that his continuist theory "discriminates between memory and episodic counterfactual thought by the requirement that [in 
the case of EM] the episodic construction system must aim at simulating an episode from the [actual] personal past" (p. 108). To say that the episodic construction system "aims at" an episode from one's actual personal past is to say that its products are in epistemic need of revision when that aim isn't met—viz., when the episodic memory does not accurately represent an episode from one's actual personal past. Even for the continuist, the role of EM is not to represent a content in a way that is "somehow fictional," but, rather, to represent things as they really were. Thus, both continuists and discontinusits will, without any arm-twisting, allow that EMs are not attitudinal imaginings, and thus not continuous with other states (such as EFT and ECT) in virtue of being attitudinal imaginings. We can reasonably conclude that attitudinal imagining is not kind $\mathrm{C}$.

This conclusion is at odds with a recent defense of discontiusim from Robins (2020), who defends discontinuism on the grounds that, unlike ECT and EFT, EMs are not attitudinal imaginings. She proposes, instead, that EMs involve taking an attitude of "seeming to remember" toward a content, which has stark differences with the attitude of imagining. Robins explains: "if I seem to remember receiving a piano for my birthday, then I take it to be the case that I did in fact receive a piano." By contrast, "when I imagine that I received a piano instead of a bicycle, I do not believe that I received the piano." In connecting the attitude of seeming to remember to "taking it to be the case," Robins is proposing that seeming to remember, unlike attitudinal imagining, is subject to belief-like norms of correctness. Supposing that seeming to remember is indeed defined, in part, by appeal to such norms, this is good grounds for thinking that EMs are not attitudinal imaginings.

The problem with this defense of discontinuism is that the continuist already accepts it. We have seen, in Michaelian's discussion of the "aims" of EM, that continuists agree that different accuracy norms apply to EMs than to EFT/ECT. Nor is there reason to think they would object to understanding those differences in norms as entailing differences in attitudes. Thus, when continuists claim that EM and EFT/ECT are all imaginings, it must not be the attitudinal sense of 'imagining' they have in mind. Whether or not EM is continuous with EFT/ECT in falling under that term appears irrelevant to their concerns.

We could instead interpret the debate between Robins and continuists as concerning which kind of psychological kind is most fundamental — attitudinal kinds or, say, neurocognitive 
kinds - with Robins arguing that a difference in attitudinal kinds is the one that should matter. But this is to take a deflationary perspective on the (dis)continuism debate. Continuists and discontinuists are then no longer disagreeing over whether EMs are cases of imagining; they are, instead, talking past each other, using 'imagining' in different senses - and disagreeing, if implicitly, over which sense corresponds to a more fundamental kind. One could argue that this is all there is to the (dis)continuism debate. But I will make the case, in the next section, that there is more to it than that.

\section{Constructive Imagining}

If the class of imagistic imaginings is too big, and the class of attitudinal imaginings too small, perhaps the class of constructive imaginings will be just right. In a Philosophy Compass article distinguishing three distinct uses of 'imagines' active in philosophy (the other two being imagistic and attitudinal imagining), Van Leeuwen (2013) characterizes constructive imagining as "a constructive process of assembling mental representations" (2013, p. 221). When we say that $X$ imagines $c$, in the constructive sense, we "express that $\mathrm{X}$ is engaged in a process of coming up with mental representations that have $c$ content" (p. 224). When we speak of constructive imagination as a capacity or faculty, we refer to "the capacity to form novel representations" (p. 224).

One might worry that this notion of constructive imagining is too broad to be of interest. Reasoning, and indeed thinking in general, would appear to involve "a constructive process of assembling mental representations." It is not immediately clear which episodes of stimulusindependent thought will not qualify as constructive imaginings. And yet, from the perspective of the (dis)continuism debate, the notion of constructive imagining gains some traction. For there is at least one salient mental process that Van Leeuwen's characterization clearly rules out as an instance of constructive imagining: perception. When we perceive the world, we enjoy a sequence of mental representations. But we don't construct a sequence of mental representations. Aside from the effects of moving our eyes and bodies, and various involuntary "top-down" effects on how perceptual inputs are processed, the sequence of representations we experience in perception is determined by how the world is outside of us. Yes, we are active agents in perceiving the world; and, yes, our cognitive systems make creative contributions to 
how that input is processed. But it would go too far to say that perceiving involves "coming up with," "constructing," or freely "assembling” representations. Perceiving remains stimulusdependent (Beck, 2018) and is thus not a kind of constructive imagining.

One might see episodic memory as similar to perception in this regard. Even if EM is not determined by what is now perceptually before us, it might seem that, in order to be EM, a mental process must be tightly constrained by one's past perceptual experiences. Suppose, for instance, that we accepted the intuitive (if now roundly rejected) view that episodic memory is a kind of replay of previously recorded and dutifully stored perceptual experience. On that sort of view, we are no more "assembling" or "constructing" a sequence of representations when replaying memory episodes than we are when having perceptual experiences. We experience the sequence in the very form in which it first impinged upon our senses. If activating this kind of replay is what it is to remember, we have a clear contrast with cases of EFT and ECT, which, by their nature, cannot be mere replays of past experience. They must instead involve the active construction or assembly of representations into some novel form. They must involve imagining in the constructive sense!

And now, were someone to come along and reject the claim that EM is a replay of past perceptual experience-holding that EM, too, is a kind of constructive simulation of perception, where we actively assemble representations in the service of representing the past, without any need for a causal connection to a past perception (Michaelian, 2016a, 2016c) - the (dis)continuism debate would be up and running between the replay theory and this new simulationist perspective. Moreover, the debate would be appropriately conceived as over whether EM, EFT, and ECT are all forms of (constructive) imagining.

While I think this is indeed the right way to think about the (dis)continuism debate, two possible concerns should be addressed. First, it is true that, even on a simulationist view such as Michaelian's, EM is subject to constraints of a kind. We saw that EM "aims" to represent the actual past and is in that sense constrained by how things actually were. For that reason, it might seem that even the simulationist cannot hold that EM is constructive imagining. However, the form of constraint just noted remains compatible with constructive imagining. After all, EFT and ECT are also constrained by how things were in the past. This is not because they are "replays" of the past, of course, but because how we represent future episodes, and how we 
represent what would have been, must, in order to serve our aims, be informed by how things have gone in the past. We are not flying free of all constraints when we aim to represent our futures, or how things would have gone had some counterfactual premise held. Instead, our $a$ posteriori knowledge of how things typically go is relied upon, and serves to constrain, such ponderings. There remains an important contrast between these broadly rational constraints, inherent in simply doing one's best to construct an accurate representation of some situation-be it the past, future, or counterfactual — and the arational constraints at work when simply replaying an earlier-recorded stimulus-dependent experience. The latter is clearly at odds with the notion of 'constructive imagining,' while the former is not.

Second, as remarked, few if any contemporary memory researchers hold that EM is indeed a simple "replay" of past perceptual experience. Instead, most—including most discontinuists - allow that EM involves a degree of "construction," a kind of active assembly of representations in the service of representing the personal past that is influenced by factors over and above whatever perceptual experiences occurred at the time. This might suggest that my characterization of the (dis)continuism debate is in accurate, in attributing to discontinuists a view they reject. And yet: strong traces of the "replay" view remain common among discontinuists, insofar as they defend transmissionist accounts of EM (Michaelian \& Robins, 2018), according to which a successful episodic remembering must recreate at least some aspects of the content of perceptual experiences that were had during the remembered episode — with the original experience effectively "transmitting" some of its content to the act of remembering. (Such transmissionist theories are closely related to "constructive" casual theories of memory (Cheng \& Werning, 2016; Michaelian, 2011; Sutton, 1998). $)^{1}$ The transmitted aspect of an EM's content can be viewed as the non-constructed part of the EM. For the content of an experience to be transmitted, in the relevant sense, an appropriate causal relation must hold between the original experience and the would-be episodic memory-one which serves to "transmit" the former's content. Typically, such content is said to be transmitted through the work of a memory

\footnotetext{
${ }^{1}$ Constructive causal theories, of the sort defended by Sutton (1998), Michaelian (2011), and Cheng \& Werning (2016), are transmissionist in allowing for successful cases of memory to involve additions and deletions to the contents of the originating experiences. The difference with transmissionism, as I will understand it, is that transmissionism as such requires no commitment to EM (as a kind) being caused by an appropriate memory trace. How there can be a transmissionist theory without such a commitment will become clearer below with the discussion of functionalism and the distinction between factive and non-factive transmissionist theories.
} 
trace (Bernecker, 2010; C. B. Martin \& Deutscher, 1966). While the precise analysis of a memory trace remains a matter of dispute, the general idea is of a mental state that is caused by an act of perception, encodes information about the perceived event, and continues to store that information until some later moment when, by suitably causing an episode of EM, it allows the event that originally caused it, and about which it carries information, to be remembered (De Brigard, 2014; Robins, 2016). The event is remembered just because the original act of perception transmits some of its content to the EM via the work of the memory trace.

Discontinuists - including the constructive causal theorists mentioned above - typically hold that successful memories must be caused, in part, by a suitable memory trace, while allowing that the content of a memory may omit aspects of — or even slightly expand upon — the content contributed by the memory trace (and so are also "constructed," to a degree) (De Brigard, 2014). We still have a clean dispute between such transmissionists, on the one hand, and simulationists (such as Michaelian), on the other, who don't think that successful EM requires any such causal condition to be met, and who therefore can propose that EM is entirely constructed, in the "constructive imagining" sense. And, indeed, this is precisely where the (dis)continuism debate typically occurs: between simulationists, like Michaelian, and "causal theorists," such as Perrin (2016) and Debus (2014), who hold that at least some content preservation-via-causation must occur in genuine EM. Hence Perrin and Michaelian's (2017) conclusion, in an overview of the (dis)continuism debate, that "the continuist-discontinuist debate may bottom out in a clash of intuitions over the necessity of causation for remembering" (p. 236).

At last, we seem to have a satisfying answer to question (3) above: to be of kind $\mathrm{C}$ is to be a constructive imagining.

\section{IV.}

And yet. If we look closer still, the debate again seems to blur.

Let us say that 'EM' is a success term if there can be no unsuccessful episodic rememberings. There are at least two things we might demand of a successful episodic memory: first, accuracy about how things were; and, second, proper causal provenance. For an EM to be accurate is for it to (more or less) accurately represent the event that it is a memory of. For it to 
bear proper causal provenance is for it to be suitably causally dependent on a past perceptual experience of the event remembered. (However, for some, proper causal provenance may be understood, quite differently, as derivation from a properly functioning episodic construction system (Michaelian, 2016c).) More on these distinctions in a moment.

First I want to highlight the point I will pursue in drawing them. It is one thing to debate whether 'episodically remembers' is a success term, and thus whether there are such things as unsuccessful cases of episodic remembering. In having that debate we might ask: is misremembering still a kind of episodic remembering? A separate question is how to understand the requirements for being a successful case of episodic remembering. Here a relevant question is: what specific kinds of accuracy and causal provenance conditions are required for the success of an EM? Two people might disagree over whether 'EM' is a success term-and thus dispute whether any cases of misremembering are instances of the mental kind episodic rememberingwhile agreeing about the conditions that must be met for an episodic remembering to be successful. For instance, the two parties might agree that a certain causal condition must be met for an episodic remembering to be successful, while disagreeing over whether states that fail to meet the causal condition can nevertheless be considered instances of the mental kind episodic remembering (EM). (We find this disagreement between Bernecker (2010) and Fernández (2019), for example). Conversely, two people might agree that 'episodically remembers' is a success term - and so agree that there are no cases of EM that are misrememberings-while disagreeing about what conditions must be met by successful EMs. For instance, one party might think that success requires the EM to be caused by a memory trace, while the other allows for successful EM in the absence of such (Michaelian, 2016c). Until these debates are clearly seen as distinct debates, there can be no clarity in the (dis)continuism debate. Further, in the process of pulling these debates apart, we will see that discontinuism appears to have the upper hand - and that, in fact, continuists seem already committed to discontinuism. That will be my argument in the balance of this section.

\section{Episodic Memory from a functionalist point of view}

Let us turn back to the success conditions of accuracy and causal provenance. If accuracy is a necessary feature of EM, then EM is factive. On factive views of EM, there is no such thing as an inaccurate episodic remembering of some feature $\mathrm{x}$ of an event $\mathrm{y}$; one's EM, to 
be an EM, must accurately enough represent things as they were. (How accurate is accurate enough can be left open.) So, factive views of EM treat 'EM' as a success term, at least insofar as accuracy is required for success. Yet, on most views of EM, accurately representing things as they were is not all that the success of an EM requires. A proper causal provenance is required in addition. After all, I might accurately represent what it was like to be on the beaches of Normandy during D-Day, on the basis of films and news reports, without successfully remembering those events. Among transmissionists and causal theorists, those who see EM as a success term will hold that all EM, in order to be EM, must not only be accurate but also bear appropriate, content-preserving causal relationships to the past episodes they serve to recall; they must be caused by memory traces encoded during the episodes remembered and, in that sense, bear proper causal provenance from one's prior experience.

However, it is important to see that there can be transmissionist views of EM that do not treat 'EM' as a success term-views that allow for misrepresentational, non-transmissive instances of EM, while nevertheless maintaining that all successful EMs will be both accurate and involve transmitted content through causation-by-a-memory-trace. (See Fernández (2019) for a non-factive view along these lines, but which lacks any appeal to memory traces.) $)^{2}$ Yet, holding that 'EM' is not a success term raises questions. For one thing, it presumes a means for typing states as EM other than by the fact that they satisfy accuracy and causal provenance requirements (where being caused by a memory trace is, for the transmissionist, essential to having proper causal provenance). Doing so might seem at odds with transmissionist views of $\mathrm{EM}$, as it might seem to suggest that representing transmitted content is not essential to the notion of being an EM after all. However, that is in fact a misunderstanding, as can be revealed by considering how a functionalist should analyze EM.

On a functionalist understanding of the nature of mental states, accuracy and proper causal provenance conditions can come into play in how EM is defined even if 'EM' is not a

\footnotetext{
${ }^{2}$ On Fernández's theory, a person S remembers that p “just in case S has some mental image $i$ such that $i$ tends to cause in $\mathrm{S}$ a disposition to believe both that $\mathrm{p}$ and that $\mathrm{S}$ experienced that $\mathrm{p}$, and $i$ tends to be caused in $\mathrm{S}$ by having experienced that p" (2019, p. 49). The phrase "tends to cause" invokes typical causes and thereby allows for nonfactivity. However, there is no appeal to memory traces as typical causes (only past perceptions), which leaves ambiguous whether Fernández's approach should be considered transmissionist. There are difficulties in omitting an appeal to memory traces - such as differentiating merely imagining from remembering, and remembering from relearning - that I cannot address here.
} 
success term. For EM (considered as a type of state) will be understood in terms of its typical causes and effects (or as the kind of state "apt" to be caused by such and such, and "apt" to cause such and such). As David Lewis explains in one of functionalism's founding documents, "the definitive characteristic of any (sort of) experience as such is its causal role, its syndrome of most typical causes and effects" (1966, p. 17, emphasis added). David Armstrong makes similar remarks in A Materialist Theory of the Mind: "The concept of a mental state is primarily the concept of a state of the person apt for bringing about a certain sort of behavior," and "apt for being brought about by a certain sort of stimulus" (1968, p. 82). Like a tuxedo at a children's birthday party, a state can be "apt" for a situation that does not obtain. Accordingly, a standard functionalist definition of pain — taken from the Stanford Encyclopedia of Philosophy's entry on functionalism-is:

The state that tends to be caused by bodily injury, to produce the belief that something is wrong with the body and the desire to be out of that state, to produce anxiety, and, in the absence of any stronger, conflicting desires, to cause wincing or moaning (Levin, 2018).

Extended to the case of EM, this suggests a transmissionist definition of EM along the lines of:

Episodic Memory: that type of occurrent state that is typically caused, in part, by a memory trace, and that has thus and such typical effects on other mental states and behavior (including, e.g., that it causes the person who has it to judge that they witnessed the event at which the memory trace originated).

Call this a functionalist transmissionist account of EM. For the functionalist transmissionistwho resists seeing 'EM' as a success term - the fact that successful EM requires the fulfillment of a causal provenance condition (via causation by a memory trace) appears in the functional definition of EM as a typical cause of EM. On such a transmissionist view, it is an essential feature of the type of state that EM is that its instances are typically caused by relevant memory traces. (By analogy, on non-factive accounts of perceptual experience, it is a typical cause of a perceptual experience as of an $x$ that one's sensory transducers are registering a signal from an $x$, even if instances of that kind - such as hallucinations - can occur in the absence of such a cause.) By defining a mental state in terms of its typical causes and effects, the functionalist allows for situations - such as misremembering (or, in the case of perception, misperceptions and hallucinations) — where an instance of the kind occurs with non-standard causes. 
Why the continuist is probably already a discontinuist

The foregoing foray into functionalism was in the service of showing how there can be a plausible transmissionist account of EM that does not treat 'EM' as a success term. The relevance of this point to the (dis)continuism debate will be clarified soon. Going forward, I will call transmissionist theories that use 'EM' as a success term "factivist transmissionist" theories; and I will call those that do not use 'EM' as a success term "functionalist transmissionist" theories. Functionalist transmissionists and simulationists, such as Michaelian (2016c), agree that EM is not factive and that 'EM' is not a success term. ${ }^{3}$ They each allow for cases of EMconsidered as a certain type of occurrent mental state or process - that are misrememberings, or merely cases of "seeming to remember." And yet they disagree on whether successful EM requires transmission of content and/or causation by a memory trace. Simulationists (and continuists) hold that it does not.

Now, to see the (dis)continuism debate in the clearest terms possible, we should focus on perspectives that, aside of their (dis)continuism disagreement, are as like-minded as possibleviews that differ only with respect to whether EM and EFT/ECT are continuous. Simulationists and factive transmissionists make a poor contrast group in this case because they differ both with respect to the factivity of EM and the (dis)continuity between EM and EFT/ECT; whereas, functionalist transmissionists and simulationists only disagree about the latter. Thus, focusing on the debate between functionalist transmissionists and simulationists will throw the disagreement fueling the (dis)continuism debate into sharpest relief.

However, when we sharpen our focus in this way, the (dis)continuism debate begins to look insubstantial. For despite the fact that simulationists allow for instances of successful EM that do not involve transmitted content, they do not deny that instances of EM typically represent content transmitted from perceptual experiences had at the time of the episode remembered. That is, for any arbitrary EM-Mary remembering the time her family visited Disney World, say - the simulationist does not deny that some causal-transmission relationship likely holds between the content of her memory and experiences she had at Disney World. They simply

\footnotetext{
${ }^{3}$ However, there is certainly room in logical space for a factivist simulationist view of Episodic Memory. Michaelian (2016c) defines EM, roughly, as any output of the episodic construction system when it is functioning reliably and is in a mode of aiming to represent the actual personal past. This definition can be transformed into a factivist simulationist definition by appending to it "... and is doing so accurately."
} 
maintain that the content's being transmitted in this way is not essential to the state's being a successful EM. Indeed, Michaelian himself notes that while "we should abandon the causal theory in favor of the simulation theory of remembering, the simulation theory likewise invokes [memory] traces" (2016c, p. 77). And further:

While simulation of a given past episode presumably often draws on information originating in the agent's experience of that particular episode, it will rarely draw exclusively on such information, and in principle it need not draw on such information at all (2016c, p. 103, emphases in original).

What matters, from a functionalist point of view, is what is typically true of an episodic memory_not what may qualify as an episodic memory "in principle." So then: for Michaelian, just how often is often? He does not explicitly say. 'Often' certainly could stand for 'typically,' in the quote above. The upshot is that the simulationist needn't disagree with the functionalist transmissionist's characterization of EM as: that type of occurrent state that is typically caused, in part, by a memory trace, and that has thus and such typical effects on other mental states and behavior (including, e.g., that it causes the person who has it to judge that they witnessed the event at which the memory trace originated).

Of course, this is not how the simulationist in fact defines EM. Comparing his simulationist view to what he calls the "causal theory of constructive memory," Michaelian notes that, while the causal theory of constructive memory is more open than other causal theories in the kinds of differences it allows between the content of an initial perceptual experience and that of a subsequent successful memory, it

nevertheless assumes that remembering necessarily involves preservation of some content between experience and retrieval. On the simulation theory, in contrast, neither the appropriate connection condition nor the approximate content similarity condition need be satisfied (2016c, p. 111).

He moves from this claim to conclusions such as:

Remembering is not different in kind from other episodic constructive processes (p. 103), And, 
We tend to assume that it is one thing to genuinely remember the past and another to imagine it, but that turns out not to be the case (p. 120).

But notice, first, that Michaelian seems to have a factive transmissionist theory (standardly called "causalism") in mind when he suggests that, on the causal theory of constructive memory, remembering "necessarily" (instead of typically) involves preservation of content. For remembering does not require preservation of content between experience and retrieval on a functionalist transmissionist account, as such transmissionist accounts allow misrememberings as instances of EM. Second, note that he emphasizes what is strictly necessary for memory when characterizing the simulation theory, and not simply what is typical. Neither the causal connection condition nor content similarity condition "need be" satisfied by a successful EM, he tells us. But this is consistent with their typically being satisfied by successful instances of EM, and by EM in general.

Thus, the respective foci on factive transmissionist accounts as adversaries and on what can possibly count as a successful memory on the simluationist theory mask the fact the simulationist and functionalist transmissionist can both accept the functionalist transmissionist definition of EM sketched above. And yet, if the continuist (simulationist) and discontinuist (functionalist transmissionist) agree on the definition of EM, how can they still disagree over whether EM is continuous with imagining? Is there really a substantial debate left to be had?

It might sound as though there is when Michaelian comments that "what it is for a subject to remember, according to the simulation theory, is for him to imagine an episode belonging to his personal past" (p. 111). Assuming that 'imagine' here means 'constructively imagine'which, we saw in previous sections, is the most charitable reading - this does not sound like the kind of state or process that typically involves transmitted content. However, Michaelian is careful to add: "it is an oversimplification...to say that remembering just is [constructively] imagining the past" (p. 105). For something to be a case of EM (successful or not), Michaelian adds that the state must be "produced by a properly functioning episodic construction system which aims to produce a representation of an episode belonging to S's personal past” (p. 105). This condition is added to distinguish remembering, as a type of mental state, from "other forms of episodic imagination," such as EFT and ECT, and from cases of merely coincidentally accurately representing some event from one's past (which Michaelian terms “merely 
imagining" the past). A natural thought is that one thing a "properly functioning episodic construction system" will do when it "aims to produce a representation of an episode belonging to S's personal past" is represent transmitted content, through a causal link to a memory trace. And, as we have seen, Michaelian seems to allow that this is so-at least "often."

Thus, it does indeed appear that even Michaelian is able to share the same definition of EM as any functionalist transmissionist who allows for a degree of construction in EM. Indeed, both sides could consistently add to the above functionalist transmissionist characterization of EM the simulationist's condition that any case of EM must be "produced by a properly functioning episodic construction system which aims to produce a representation of an episode belonging to S's personal past" to arrive at a comprehensive characterization that preserves the emphases of each. This would give us the following combined definition of EM:

Episodic Memory: that type of occurrent state that is typically caused, in part, by a relevant memory, and that has thus and such typical effects on other mental states and behavior (including, e.g., that it causes the person who has it to judge that they witnessed the event at which the memory trace originated) AND that is produced by a properly functioning episodic construction system which aims to produce a representation of an episode belonging to $S$ 's personal past.

Short of an argument from the simulationist that EM does not even typically preserve transmitted content via a memory trace, both sides seem to agree on their basic characterization of EM. Differences only remain at the outer reaches of each theory. The continuist simulationist holds that cases of successful episodic memory that preserve no transmitted content from a prior perceptual experience are possible in principle (Michaelian, 2016c, p. 103); while the (functionalist transmissionist) discontinuist holds that such episodes should never be considered successful memories, even if they still count as EMs in satisfying the functional syndrome definitive of such. In short, the disagreement concerns not which mental episodes are cases of EM-here they agree — nor on how EM is to be defined, but on whether or not some in a small subset of EMs are to be considered successful EMs. It would be wrong to view that dispute as a disagreement over whether EM is, like EFT and ECT, a kind of constructive imagining — or, indeed, over whether EM and EFT/ECT are continuous with each other. 
Return now to the factive transmissionist view (which coheres with "causalism" or "the causal theory of memory" is it is most commonly defended). Here there is a deeper disagreement with simulationism. The factivist doesn't just hold that EM typically preserves content transmitted from a past perceptual episode, but asserts, more stringently, that there simply are no cases of EM that fail to preserve such content. Here we see a clear disagreement with the simulationist over which mental episodes count as EM. Many mental episodes that the factivist doesn't count as EM at all—because they are misrememberings - are still instances of EM for the simulationist. (For although the simulationist requires that EM is the product of a "reliable" process, a reliable one needn't be infallible.) When this difference is combined with the fact that the simulationist allows, in principle, for successful rememberings that preserve no content via a memory trace, while the factivist transmissionist does not, we look to have something more like a disagreement about the nature of memory. Yet, though there is indeed a disagreement about memory here, it has very little to do with whether memory is properly viewed as constructive imagining. For one thing, the main disagreement now is over whether memory is factive. This is a disagreement that the factive transmissionist (such as Debus (2014)) also shares with functionalist transmissionists (such as — with some amendments_-Fernández (2019)), despite their both rejecting the idea that remembering is constructive imagining. And while it remains a difference that the simulationist allows for successful EM that does not preserve transmitted content, we have seen that Michaelian's own simulationist view does not require that most, or even very many, instances of successful EM are cases of constructive imagining - only that it is possible for there to be some.

It may now seem that the entire debate has been a mirage, caused by the failure to appreciate two things: the possibility of a functionalist (and non-factive) transmissionist view, and the fact that Michaelian's simulationism is consistent with a memory trace being a typical cause of episodic memories. If the combined functionalist-transmissionist and simulationist definition of EM above is correct, then EM is not, as a type, constructive imagining. For constructive imagining, as a type, is not typically caused by a memory trace, and therefore not constrained to represent content transmitted from a past perception. A-events and B-events (recall Section 1) are not all events of kind C. Thus, whether or not EFT and ECT are themselves well-viewed as constructive imaginings, EM will not be continuous with EFT and ECT in falling under the kind 'constructive imagining.' (Note that, while previous defenses of 
discontinuism have been tethered to factive causalist theories of memory, both functionalist transmissionists and simulationists can accept discontinuism while rejecting causalism-where causalism is construed as a factive theory. In general, discontinuism does not require a factive theory of memory.)

A possible objection - echoing an earlier one of my own - is that if my characterization of kind $\mathrm{C}$ as constructive imagining makes the debate an obvious win for discontinuism, this casts doubt on constructive imagining really being the kind at issue. My reply is that identifying the notion of constructive imagining as kind $\mathrm{C}$ did not leave us with an obvious victor. Instead, it left us roughly where continuists and discontinuists already saw themselves: as differing, somehow, over the role of causal connections in memory. It was only once we picked apart the question of whether any token instance of EM must, to be a case of EM, bear an appropriate causal connection to the event it represents (the factivity question) from the question of whether EM, as a type of state, should be said to have something like memory traces as a typical cause (the success condition question) that things started to tilt in favor of discontinuism.

V.

Does discontinuism thus win the (dis)continuism debate? Not necessarily. The proper conclusion is that we can now better see what kinds of responses will be necessary on the part of the continuist.

One possible response for the continuist is to reject the claim that a memory trace is a typical cause of EM. There are different ways this could be done. One is to question the coherence of the very idea of a memory trace; another is to argue that, as a matter of empirical fact, there is nothing in the human brain that answers to the notion of a memory trace - at least, not for the vast majority of events that we are pre-theoretically inclined to identify as episodic rememberings. If either of these theses is correct, then the functionalist characterization of EM cannot appeal to a memory trace as a typical cause. This would remove the main barrier to seeing EM as a sub-set of the constructive imaginings. For, unlike attitudinal imaginings, it is no barrier on being a constructive imagining that a mental state should be subject to norms of correctness, or aim to get things right. The barrier we located was that a state cannot be a case of 
constructive imagining if it is constrained in roughly the way that stimulus-dependent perceptual experience is constrained; and memory traces, as we have understood them, plausibly impose that kind of constraint on the memories they cause. However, articulating a theory of memoryand of successful memory, in particular - that does without memory traces is no mean feat, whatever ambiguities still lurk in the notion.

A second form of response is to reject functionalism, along with its assumption that mental states are to be typed by their typical causes and effects. For the continuist, this will require, inter alia, articulating an alternative means for typing mental states that still allows for EM to be non-factive. Possibilities include typing EM by its neurological properties (assuming these are not themselves functionally individuated), or by its phenomenology. Going this route, it may become unclear why EM - so typed - should be considered a form of constructive imagining, as there are unlikely to be clear links between such kinds and the notion of constructive imagining. (Note, also, that talk of a "reliably" functioning system (Michaelian, 2016c) remains inherently functionalist: to function reliably is to typically move from thus and such kinds of inputs to thus and such kinds of outputs. A system can thus be functioning reliably when it moves from an unusual sort of input to its normal type of output).

An alternative strategy — and my favored possible future for continuism — is to argue that memory traces are typical causes of EFT and ECT in addition to EM. There are significant barriers to motivating and defending such a view, which cannot be discussed here. At a minimum, it will require substantive revision of the standard understanding of memory traces. On one such revision, memory traces impose such slight constraints on the episodes they typically cause that all such episodes can still qualify as constructive imaginings. This could be the case if, for instance, memory traces only encode information about spatial layouts and are not temporally keyed to specific past events (Hassabis \& Maguire, 2009; Maguire \& Mullally, 2013). Of course, such a view raises the question of whether memory traces can still do the theoretical work normally required of them, such as in distinguishing remembering from relearning (Michaelian, 2016b; Robins, 2017). A related alternative is to hold that, while memory traces are typical causes of both EM and EFT/ECT, and while this prevents all three from being constructive imaginings, their common connection to memory traces renders all three instances of some other psychological kind, such as judgments (Langland-Hassan, 2015). This 
would be a backdoor vindication of continuism —one that leaves us with the challenge of specifying the nature of the relevant kind, while simultaneously articulating what distinguishes successful from unsuccessful memories.

Acknowledgments: Special thanks to Sarah Robins and two anonymous referees for this journal for helpful feedback that improved this paper. 


\section{References}

Addis, D. R. (2020). Mental Time Travel? A Neurocognitive Model of Event Simulation. Review of Philosophy and Psychology, 11(2), 233-259. doi:10.1007/s13164-020-00470-0

Arcangeli, M. (2018). Supposition and the Imaginative Realm: A Philosophical Inquiry. New York: Routledge.

Arcangeli, M. (2019). The Two Faces of Mental Imagery. Philosophy and Phenomenological Research, $O(0)$. doi:10.1111/phpr.12589

Atance, C. M. (2008). Future thinking in young children. Current Directions in Psychological Science, 17(4), 295-298.

Beck, J. (2018). Marking the Perception-Cognition Boundary: The Criterion of Stimulus-Dependence. Australasian Journal of Philosophy, 96(2), 319-334. doi:10.1080/00048402.2017.1329329

Bernecker, S. (2010). Memory: A philosophical study. Oxford: Oxford University Press.

Byrne, A. (2007). Possibility and Imagination. Phiosophical Perspectives, 21(1), 125-144.

Cheng, S., \& Werning, M. (2016). What is episodic memory if it is a natural kind? Synthese, 193(5), 1345-1385. doi:10.1007/s11229-014-0628-6

Currie, G., \& Ravenscroft, I. (2002). Recreative Minds: Imagination in Philosophy and Psychology. Oxford: Clarendon Press.

De Brigard, F. (2014). The Nature of Memory Traces. Philosophy Compass, 9(6), 402-414. doi:10.1111/phc3.12133

De Brigard, F., Addis, D. R., Ford, J. H., Schacter, D. L., \& Giovanello, K. S. (2013). Remembering what could have happened: Neural correlates of episodic counterfactual thinking. Neuropsychologia, 51(12), 2401-2414.

Debus, D. (2008). Experiencing the Past: A Relational Account of Recollective Memory. Dialectica, 62(4), 405-432. doi:10.1111/j.1746-8361.2008.01165.x

Debus, D. (2014). 'Mental time travel': Remembering the past, imagining the future, and the particularity of events. Review of Philosophy and Psychology, 5(3), 333-350.

Fernández, J. (2019). Memory: A self-referential account. New York: Oxford University Press.

Garry, M., Manning, C. G., Loftus, E. F., \& Sherman, S. J. (1996). Imagination inflation: Imagining a childhood event inflates confidence that it occurred. Psychonomic Bulletin \& Review, 3(2), 208214.

Hassabis, D., Kumaran, D., Vann, S. D., \& Maguire, E. A. (2007). Patients with hippocampal amnesia cannot imagine new experiences. Proceedings of the National Academy of Sciences of the United States of America, 104, 1726-1731.

Hassabis, D., \& Maguire, E. A. (2009). The construction system of the brain. Philosophical Transactions of the Royal Society B: Biological Sciences, 364(1521), 1263-1271.

Kind, A. (2001). Putting the Image Back in Imagination. Philosophy and Phenomenological Research, 62(1), 85-109.

Kind, A. (2016). Introduction: Exploring imagination. In A. Kind (Ed.), The Routledge Handbook of Philosophy of Imagination (pp. 1-12). New York: Routledge.

Langland-Hassan, P. (2015). Imaginative Attitudes. Philosophy and Phenomenological Research, 90(3), 664-686. doi:10.1111/phpr.12115

Langland-Hassan, P. (2020). Explaining Imagination. Oxford: Oxford University Press.

Levin, J. (2018). Functionalism. In E. N. Zalta (Ed.), The Stanford Encyclopedia of Philosophy (Fall 2018 ed.).

Lewis, D. K. (1966). An argument for the identity theory. The Journal of Philosophy, 63(1), 17-25.

Liao, S.-y., \& Doggett, T. (2014). The Imagination Box. The Journal of Philosophy, 111(5), 259-275.

Liao, S.-y., \& Gendler, T. (2020). Imagination. In E. N. Zalta (Ed.), The Stanford Encyclopedia of

Philosophy (Summer 2020 ed.). 
Loftus, E. F., \& Pickrell, J. E. (1995). The formation of false memories. Psychiatric Annals, 25(12), 720725. doi:10.3928/0048-5713-19951201-07

Maguire, E. A., \& Mullally, S. L. (2013). The hippocampus: a manifesto for change. Journal of Experimental Psychology: General, 142(4), 1180.

Martin, C. B., \& Deutscher, M. (1966). Remembering. The Philosophical Review, 75(2), 161-196. doi:10.2307/2183082

Martin, M. G. F. (2002). The Transparency of Experience. Mind and Language, 17(4), 376-425.

Michaelian, K. (2011). Generative memory. Philosophical Psychology, 24(3), 323-342. doi:10.1080/09515089.2011.559623

Michaelian, K. (2016a). Against Discontinuism. In K. Michaelian, S. B. Klein, \& K. K. Szpunar (Eds.), Seeing the Future: Theoretical Perspectives on Future-Oriented Mental Time Travel. Oxford: Oxford University Press.

Michaelian, K. (2016b). Confabulating, misremembering, relearning: The simulation theory of memory and unsuccessful remembering. Frontiers in Psychology, 7, 1857.

Michaelian, K. (2016c). Mental Time Travel: Episodic Memory and Our Knowledge of the Personal Past. Cambridge, MA: MIT Press.

Michaelian, K., \& Robins, S. (2018). Beyond the causal theory? Fifty years after Martin and Deutscher. In K. Michaelian, D. Debus, \& D. Perrin (Eds.), New Directions in the Philosophy of Memory (pp. 13-32). London: Routledge.

Nanay, B. (2018). Multimodal mental imagery. Cortex, 105, 125-134. doi:https://doi.org/10.1016/j.cortex.2017.07.006

Noordhof, P. (2002). Imagining objects and imagining experiences. Mind and Language, 17(4), 426-455.

Peacocke, C. (1985). Imagination, Possibility and Experience. In J. Foster \& H. Robinson (Eds.), Essays on Berkeley: a Teracentennial Celebration. Oxford: Clarendon Press.

Perrin, D. (2016). Asymmetries in Subjective Time. In K. Michaelian, S. B. Klein, \& K. K. Szpunar (Eds.), Seeing the Future: Theoretical Perspectives on Future-Oriented Mental Time Travel (pp. 39-61). Oxford: Oxford University Press.

Perrin, D., \& Michaelian, K. (2017). Memory as mental time travel. In S. Bernecker \& K. Michaelian (Eds.), The Routledge handbook of philosophy of memory (pp. 228-239). New York: Routledge.

Robins, S. (2016). Representing the past: memory traces and the causal theory of memory. Philosophical Studies, 173(11), 2993-3013. doi:10.1007/s11098-016-0647-x

Robins, S. (2017). Memory traces. In K. Michaelian \& S. Bernecker (Eds.), The Routledge handbook of philosophy of memory (pp. 76-87). London: Routledge.

Robins, S. (2020). Defending Discontinuism, Naturally. Review of Philosophy and Psychology. doi:10.1007/s13164-020-00462-0

Schacter, D. L., \& Addis, D. R. (2007). The cognitive neuroscience of constructive memory: remembering the past and imagining the future. The Philosophical Transactions of the Royal Society B: Biological Sciences, 362, 773-786.

Schacter, D. L., Addis, D. R., \& Buckner, R. L. (2007). Remembering the past to imagine the future: the prospective brain. Nat Rev Neurosci, 8(9), 657-661. doi:nrn2213 [pii]

$10.1038 / \mathrm{nrn} 2213$

Searle, J. (1983). Intentionality: an essay in the philosophy of mind. Cambrdige: Cambridge University Press.

Sutton, J. (1998). Philosophy and memory traces: Descartes to connectionism. Cambridge: Cambridge University Press.

Szpunar, K. K., Watson, J. M., \& McDermott, K. B. (2007). Neural substrates of envisioning the future. Proceedings of the National Academy of Sciences, 104(2), 642-647.

Van Leeuwen, N. (2013). The Meanings of "Imagine" Part I: Constructive Imagination. Philosophy Compass, 8(3), 220-230. 
Van Leeuwen, N. (2014). The meanings of "imagine" part II: Attitude and action. Philosophy Compass, 9(11), 791-802.

Williamson, T. (2016). Knowing by Imagining. In A. Kind \& P. Kung (Eds.), Knowledge through imagination. Oxford: Oxford University Press. 